\title{
Psychophysical Stress and Individual Susceptibility to Breast Cancer
}

Serena Bertozzi ${ }^{1}$, Sergio Bernardi ${ }^{2 *}$, Ambrogio P. Londero ${ }^{1}$, Barbara Petronio ${ }^{3}$, Alessandro Balani ${ }^{3}$, Andrea Risaliti ${ }^{1}$ and Carla Cedolini ${ }^{1}$

${ }^{1}$ University of Udine, Udine, Italy

${ }^{2}$ Department of Surgery, Hospital of Latisana, Italy

${ }^{3}$ Department of Surgery, Hospital of Gorizia, Italy

\begin{abstract}
Many epidemiological studies correlated stress to cancer development. Recently was found a significantly increased breast cancer risk in women exercising job authority that was considered to be a stressful situation. These epidemiological links have been widely questioned and criticized but without getting a definitive answer. As a consequence, prospective studies are required in order to determine the role of distressful emotions on the natural history of cancer, with the aim to promptly identify cancer susceptible patients and, most important, to reduce their cancer predisposition by improving their psychophysical health status.
\end{abstract}

\section{Keywords: Cancer; Breast cancer; Stress}

Environmental risk factors for cancer have been widely investigated, with the conviction that people's sickness derives from factors attacking them from the outside. At the same time, little attention was directed to what determines the resistance or the susceptibility to cancer and only few authors have wondered why certain individuals, similarly exposed to the same agent, remain healthy or become ill.

The possible association between distressful events and cancer development has already been described in the literature, but most studies about this argument are very questionable from a statistical point of view [1-4]. In fact, since cancer is a cause of stress itself, it may be difficult to determine which comes first, as well as it is hard to establish exactly when malignant growth began compared to when it was first detected, making it equally difficult to prove any temporal relationship.

Moreover, another problematic aspect of stress is the general disagreement on its definition and evaluation, and the strong interpersonal variability of stress perception makes almost impossible to classify stress intensity on an objectifiable scale. In order to take into account these methodological limitations by studying the correlation between stress and cancer, some authors investigated the cancer incidence in a population who simultaneously underwent an objectifiable stress, such as that of Leningrad during the siege in World War II in 1941-1944, and demonstrated that the experience of severe starvation and stress during childhood and adolescence may have longterm effects on cancer in the surviving men and women [5].

Other studies provided some evidence of cancer predisposition in a group of patients with a reliable psychological portrait: in particular, the major characteristics of individuals prone to cancer appear to be their frequent feelings of hopelessness and helplessness, an inability to openly express anger or resentment, an unusual amount of self dislike and distress, and their lack of a meaningful emotional relationship [6,7].

Although the mechanisms of stress, involved in cancer susceptibility, are still to be clarified, a possible explanation is provided by the "General Adaptation Syndrome" described by Hans Selye in 1950 with its outcome the "Diseases of Adaptation" and its implications for an altered functioning of the immune system that might predispose to malignancy $[8,9]$. Furthermore, some authors suggested that chronic stress, through beta-adrenergic stimulation and the consequent increased exposure to stress hormones such as cortisol and catecholamines, can induce two synergistic pathways that result in accumulation of DNA damage, and consequently in an increased cancer risk $[10,11]$.

Among the different, possible sources of psychophysical stress, work related stress results one of the most investigated in the current literature. In fact, a recent study observed a significantly increased breast cancer risk in women exercising job authority, defined as control over others' work, and especially with longer duration of holding a professional/managerial job position [12]. An objection one could move against this kind of conclusion is that in the most cases high occupational positions probably correlate with high social status and educational levels, and thus selecting a group of women who generally are more likely to undergo regular screening and extra-screening examinations, and consequently may have a higher incidence of breast cancers diagnosed. Anyway, these authors suggested that job authority holding caused stressful interpersonal experiences which may promote breast cancer development through a prolonged dysregulation of the glucocorticoid system and a breast tissue exposure to chronically elevated cortisol. On the other hand, a recent meta-analysis excluded any significant correlation between work related stress, measured and defined as job strain, and the development of breast cancer, as well as of other frequent cancers [13].

In our experience, the $42 \%$ of women who were operated for breast cancer in our Department of Surgery between 2002 and 2012, referred one or more stressful events during the previous two years, including a relative loss, a familiar wrangle, or a work problem. Therefore, although stressful events were not proved to be a direct cause of cancer, in our opinion, they might promote or even accelerate the development of a preexisting malignancy. And actually another recent study suggests that perceived stress may be a contributing factor to breast cancer, when combined with potentially risky lifestyle behaviors [14].

Analyzing the possible biases which may influence the causal and temporal correlation between personal history of stress and cancer diagnosis, in our opinion, women who underwent suffering for a period of their life, may have neglected their health in that period and avoided the check-up that they would have regularly made if they would not

${ }^{*}$ Corresponding author: Sergio Berardi, Department of Surgery, Hospital of Latisana, Via Sabbionera, 45, 33053 Latisana (UD), Italy, Tel: +39 347 2335937; E-mail: dr.bertozzi@gmail.com

Received January 07, 2014; Accepted January 28, 2014; Published February 05, 2014

Citation: Bertozzi S, Bernardi S, Londero AP, Petronio B, Balani A, et al. (2014) Psychophysical Stress and Individual Susceptibility to Breast Cancer. Surgery Curr Res 4: 163. doi:10.4172/2161-1076.1000163

Copyright: (c) 2014 Bertozzi S, et al. This is an open-access article distributed under the terms of the Creative Commons Attribution License, which permits unrestricted use, distribution, and reproduction in any medium, provided the original author and source are credited. 
have had worse things to deal with. As a consequence, breast cancer diagnosis may happen just after their stress resolution, or just after starting again to take care of themselves.

In conclusion, prospective studies are required on a sufficient number of patients, in order to determine the real role of distressful emotions on the natural history of cancer, with the aim to promptly identify cancer susceptible patients and, most important, to reduce their cancer predisposition by improving their psychophysical health status.

\section{Conflict of Interest}

The Authors disclose any conflict of interest for what concerns the present work.

\section{References}

1. Kowal SJ (1955) Emotions as a cause of cancer; 18th and 19th century contributions. Psychoanal Rev 42: 217-227.

2. Rosch, PJ (1984) Stress and Cancer, in Cooper, CL ed. Psychosocial Stress and Cancer. John Wiley \& Sons, Chichester.

3. Blumberg EM, West PM, Ellis FW (1954) A possible relationship between psychological factors and human cancer. Psychosom Med 16: 277-286.

4. Cooper CL (1984) Psychosocial Stress and Cancer, John Wiley \& Sons, Chichester.
5. Koupil I, Plavinskaja S, Parfenova N, Shestov DB, Danziger PD, et al. (2009) Cancer mortality in women and men who survived the siege of Leningrad (1941-1944). Int J Cancer 124: 1416-1421.

6. Leshan L, Worthington RE (1956) Some recurrent life history patterns observed in patients with malignant disease. J Nerv Ment Dis 124: 460-465.

7. Schmale AH, Iker HD (1966) The Affect of hopelessness and the development of cancer. Psychosom Med 28: 714-721.

8. Rosch PJ (2008) Stress and Cancer: Disorders of Communication, Control and Civilization.

9. Burnet FM (1971) Immunological surveillance in neoplasia. Transplant Rev 7 : 3-25.

10. Flint MS, Bovbjerg DH (2012) DNA damage as a result of psychological stress: implications for breast cancer. Breast Cancer Res 14: 320 .

11. Hara MR, Kovacs JJ, Whalen EJ, Rajagopal S, Strachan RT, et al. (2011) A stress response pathway regulates DNA damage through î22-adrenoreceptors and $\hat{I}^{2}$-arrestin-1. Nature 477: 349-353.

12. Pudrovska T, Carr D, McFarland M, Collins C (2013) Higher-status occupations and breast cancer: a life-course stress approach. Soc Sci Med 89: 53-61.

13. Heikkilä K, Nyberg ST, Theorell T, Fransson El, Alfredsson L, et al. (2013) Work stress and risk of cancer: meta-analysis of 5700 incident cancer events in 116,000 European men and women. BMJ 346: f165.

14. Wang L, Liao WC, Tsai CJ, Wang LR, Mao IF, et al. (2013) The effects of perceived stress and life style leading to breast cancer. Women Health 53 : $20-40$ 